\title{
How to Avoid Primary Caesarean Section? A Five-Year Experience Report from a Level 2 Facility in Dakar Senegal
}

\author{
Mame Diarra Ndiaye Gueye, Mamour Gueye*, Magatte Mbaye, Abdelouahed Chraibi, Aliou Diouf, \\ Mouhamadou Wade, Moussa Diallo, Omar Gassama, Mor Cisse, Youssoupha Toure, \\ Moustapha Thiam, Jean Charles Moreau
}

Gynecologic and Obstetric Clinic, Aristide Le Dantec Teaching Hospital, Cheikh Anta DIOP University, Dakar, Senegal

Email: *mamourmb@gmail.com

How to cite this paper: Gueye, M.D.N., Gueye, M., Mbaye, M., Chraibi, A., Diouf, A., Wade, M., Diallo, M., Gassama, O., Cisse, M., Toure, Y., Thiam, M. and Moreau, J.C. (2017) How to Avoid Primary Caesarean Section? A Five-Year Experience Report from a Level 2 Facility in Dakar Senegal. Open Journal of Obstetrics and Gynecology, 7, 1174-1182. https://doi.org/10.4236/ojog.2017.712119

Received: September 25, 2017 Accepted: November 12, 2017 Published: November 15, 2017

Copyright ( 2017 by authors and Scientific Research Publishing Inc. This work is licensed under the Creative Commons Attribution International License (CC BY 4.0).

http://creativecommons.org/licenses/by/4.0/ (c) (i) Open Access

\begin{abstract}
Objectives: The aim of this study was to analyse key factors and main indications of primary caesarean sections and find out ways to reduce the rising rates. Patients and method: This was a longitudinal and retrospective study carried out from 1 January 2012 to 31 December 2016. The study included all patients in whom a primary CS was performed. A previous uterine scar was a non-inclusion criterion. We analysed the main indications and their trends during these five years, Apgar score at the $5^{\text {th }}$ minute according to the course of caesarean section rate and the impact of daily audit. Data were collected retrospectively from 2012 to 2015, then prospectively in 2016 using a Filemaker database. Data were analysed with SPSS 21 software, Mac version. Averages were calculated for quantitative data and percentage for qualitative ones. The statistical tests used were the Pearson Chi2 test. The differences observed were considered significant when the $p$ value was less than 0.05 . Results: During the study period, we registered 21.308 deliveries and 6.292 caesarean sections (29.5\%). Primary CS concerned $72.5 \%$ of overall CS. The main indications were suspicious of fetal distress $(29.1 \%)$, obstructed or prolonged labour $(21.7 \%)$, breech and twin delivery with respectively $8.2 \%$ and $5.2 \%$. We registered more vaginal deliveries with induction of labour: $81.4 \%$ versus $75.2 \%$. An obstetrical audit allowed better management of labour and decrease of CS rate. Conclusion: We need to focus on diagnosis of fetal distress, management of breech presentation in twin delivery and singleton. The induction of labour can be an effective alternative in some indications. An obstetrical audit is necessary to reverse caesarean section rate.
\end{abstract}




\section{Keywords}

Caesarean Section Rate, Indications, Apgar Score, Obstetrical Audit

\section{Introduction}

Caesarean section (CS) is a surgical procedure used commonly to reduce maternal and neonatal morbidity. However, CS rate without medical indications can expose mothers and newborns to unnecessary risks [1]. According to the World Health Organization (WHO), an appropriate CS rate should be between 5 and $15 \%$ [2]. CS rate is increasing steadily in many countries [2]. In several countries, CS rate reaches $30 \%$ or more: $31.1 \%$ in the United States of America in 2006 [3], more than 30\% in many European countries and 30.5\% in Singapore in 2003 [4]. In Senegal, a Sub-Saharan low-income country, the national CS rate in 2014 was $4.4 \%$ with huge disparities between facilities: from $0.1 \%$ in remote areas to $50.2 \%$ in the capital [5]. However, an analysis needs to be done to identify the sources of what appears to be, on one hand, an inadequate access to CS and, on the other hand, an unnecessary indication of CS. According to Robson's Ten Group classification system, one of the steps of maintaining an appropriate CS rate is an assessment of obstetrical management [6]. Many studies showed the major contribution of Group 5 (previous caesarean section, singleton, cephalic, after 37 weeks' gestation) in the increase of CS rate [4] [7] [8].

We have carried out this study to identify the key factors leading to CS and find the means and ways to avoid unnecessary primary CS.

\section{Patients and Method}

This longitudinal and retrospective study is taking into account the period between 1 January 2012 and 31 December 2016 in a level 2 perinatal care facility in Dakar the capital of Senegal.

It is based on all primary CS patients. Consequently, a previous uterine scar was a non-inclusion criterion.

In fact, medical data were recorded retrospectively between January the $1^{\text {st }}$ 2012 and December $31^{\text {th }}$ 2015. After this date, data are recorded on a daily basis using Filemaker 15 software. Since 2015, an audit is carried out day by day to analyse, a posteriori, CS indications.

Multiparous are patients who gave birth once at least.

Then, women were classified through Robson's Ten Group Classification as it appears in Table 1 [9] enabling us to assess the contribution of each group in primary caesarean sections. Besides, we have classified indications of CS according to a group of main indications which are the following: obstructed or prolonged labour, suspected fetal distress, breech presentation, twin delivery, antepartum haemorrhage, high blood pressure associated to pregnancy and others. 
Table 1. Robson's ten groups classification.

\begin{tabular}{|c|c|}
\hline Groups & Definition of groups \\
\hline 1 & Nulliparous with single cephalic pregnancy, $\geq 37$ weeks gestation in spontaneous labour \\
\hline 2 & $\begin{array}{l}\text { Nulliparous with single cephalic pregnancy, } \geq 37 \text { weeks gestation who } \\
\text { either had labour induced or were delivered by CS before labour }\end{array}$ \\
\hline 3 & $\begin{array}{l}\text { Multiparous without a previous uterine scar, with single cephalic pregnancy, } \\
\qquad \geq 37 \text { weeks gestation in spontaneous labour }\end{array}$ \\
\hline 4 & $\begin{array}{l}\text { Multiparous without a previous uterine scar, with single cephalic pregnancy, } \geq 37 \\
\text { weeks gestation who either had labour induced or were delivered by CS before labour }\end{array}$ \\
\hline 5 & $\begin{array}{l}\text { All multiparous with at least one previous uterine scar, with single } \\
\text { cephalic pregnancy, } \geq 37 \text { weeks gestation }\end{array}$ \\
\hline 6 & All nulliparous women with a single breech pregnancy \\
\hline 7 & $\begin{array}{l}\text { All multiparous women with a single breech pregnancy including } \\
\text { women with previous uterine scars }\end{array}$ \\
\hline 8 & All women with multiple pregnancies including women with previous uterine scars \\
\hline 9 & $\begin{array}{l}\text { All women with a single pregnancy with a transverse or oblique lie, } \\
\text { including women with previous uterine scars }\end{array}$ \\
\hline 10 & $\begin{array}{c}\text { All women with a single cephalic pregnancy } \geq 36 \text { weeks gestation, } \\
\text { including women with previous scars }\end{array}$ \\
\hline
\end{tabular}

Obstructed labour is a mechanical obstruction resulting from fetopelvic disproportion. Prolonged labour is due to dynamic labour disorders with inadequate uterine contractions [10]. The diagnosis was made in two main forms: a stationary cervical dilation for 2 hours after $4 \mathrm{~cm}$ or a latent phase that lasts more than 12 hours for primiparous and 8 hours for multiparous.

Regarding Fetal distress, it is suspected when an abnormal fetal heart rate occurred at intermittent auscultation (less than 110 or more than 160 pulses per minute) associated to meconium in amniotic fluid.

Antepartum haemorrhage involved placental abruption and placenta praevia.

Impact of induction of labour was also assessed. Induction of labour is a method of artificial initiation of labour [11]. We used an E2 prostaglandin analogue. Oral or vaginal route were used with $25 \mu \mathrm{g}$ per 6 hours. A maximum of 4 doses was given.

New-born characteristics were analysed using mainly Apgar score.

Data were analysed with the help of SPSS 21 software, Mac version. We resorted to the calculation of the Average for quantitative data whereas the qualitative ones were expressed in percentages. Pearson Chi2 test or Fisher exact test were used accordingly. The differences observed were seen as significant when the $p$ value was less than 0.05 .

\section{Results}

During the study period, we have registered 21.308 deliveries and 6.292 caesarean sections (29.5\%). Women with unscarred uterus represented 18.933 and a primary CS was performed on 4.564 which is equal to $72.5 \%$ of overall CS. 
The final sample representing patients with unscarred uterus and undergoing CS was 4.564 patients. With regard to the age of patients, the average was 27.2 years (from 13 to 47 years old). Multiparous represented nearly half of the sample (49.7\%).

Robson groups 1 and 3, respectively $35.9 \%$ and $28.8 \%$, were the most represented among patients who have experienced primary caesarean.

Table 2 represents the contribution of each of Robson's Ten Groups to primary CS.

The most common indication of CS appears to be foetal distress (29.1\%). However, only $6.6 \%$ of these new-borns had an Apgar score less than 7 at the $5^{\text {th }}$ minute.

Table 3, representing the trends of deliveries during the 5 years, has revealed a

Table 2. Distribution of patients according to Robson's Ten groups classification.

\begin{tabular}{ccc}
\hline Group & Number of primary $\mathrm{CS}^{*}(\mathrm{n})$ & Percentage (\%) \\
\hline $\mathbf{1}$ & 1723 & 35.9 \\
$\mathbf{3}$ & 156 & 3.3 \\
$\mathbf{4}$ & 1381 & 28.8 \\
$\mathbf{5}$ & 135 & 2.8 \\
$\mathbf{6}$ & - & - \\
7 & 213 & 4.4 \\
8 & 240 & 5 \\
9 & 435 & 9.1 \\
10 & 70 & 1.5 \\
Total & 441 & 9.2 \\
\hline
\end{tabular}

${ }^{*} \mathrm{CS}=$ caesarean section.

Table 3. Trends of delivery through five years.

\begin{tabular}{ccccccc}
\hline Year Data & 2012 & 2013 & 2014 & 2015 & 2016 & p \\
\hline Number of delivery & 2801 & 3094 & 4251 & 4223 & 4564 \\
Caesarean section & $1070(38.2 \%)$ & $635(20.5 \%)$ & $955(22.5 \%)$ & $1029(24.4 \%)$ & $875(19.2 \%)$ & 0.000 \\
Preeclampsia-eclampsia & $163(22 \%)$ & $164(12 \%)$ & $202(12.5 \%)$ & $192(10.7 \%)$ & $237(9.7 \%)$ & 0.000 \\
Prolonged or & $458(16.2 \%)$ & $217(6.8 \%)$ & $344(7.9 \%)$ & $273(6.3 \%)$ & $219(4.7 \%)$ & 0.000 \\
Obstructed labour & & & & & & \\
Labour Abnormalities* & $1234(44.4 \%)$ & $1672(54.4 \%)$ & $2118(50.3 \%) 2282(54.3 \%)$ & $2237(49.2 \%)$ & 0.000 \\
Induction of labour & $23(0.9 \%)$ & $48(1.6 \%)$ & $75(1.8 \%)$ & $28(0.7 \%)$ & $164(3.7 \%)$ & 0.000 \\
Vacuum extractor & $24(0.8 \%)$ & $1(0.03 \%)$ & $81(1.9 \%)$ & $28(0.6 \%)$ & $35(0.8 \%)$ & 0.000 \\
forceps and manoeuvres & & & & & & \\
Apgar score < & $65(2.3 \%)$ & $23(0.7 \%)$ & $46(1.1 \%)$ & $86(2 \%)$ & $123(2.6 \%)$ & 0.000 \\
\hline
\end{tabular}

*Labour abnormalities: fetal distress, premature rupture of membranes, high blood pressure and their complications, twin delivery, other presentation than vertex. 
crescent number of deliveries and a variable CS rate. The lowest CS rate was achieved in 2016 (19.2\%) and the highest one was registered in 2012. The lowest rate of obstructed labour and prolonged labour was registered in 2016 (4.7\%) and the highest rate in 2012 (Table 4).

Senior residents performed regularly an obstetrical audit during year 2016, at least 5 days a week.

The rate of Apgar score below 7 ranged between $0.7 \%$ and $2.6 \%$. The lowest rate was obtained in 2013.

Breech presentation of the first twin was the main indication of CS in twin delivery.

CS rate was variable through the 5 years. In 2013 we observed $38.5 \%$ of caesarean in twin delivery with $0.5 \%$ of Apgar score below 7. In 2015 we noticed the highest CS rate (51.3\%) and the highest Apgar score below 7 (4.3\%). The Apgar score was not related to the CS rate. A lower neonatal morbidity was registered when the CS rate was ranged between $38.5 \%$ and $46.5 \%$ (Figure 1).

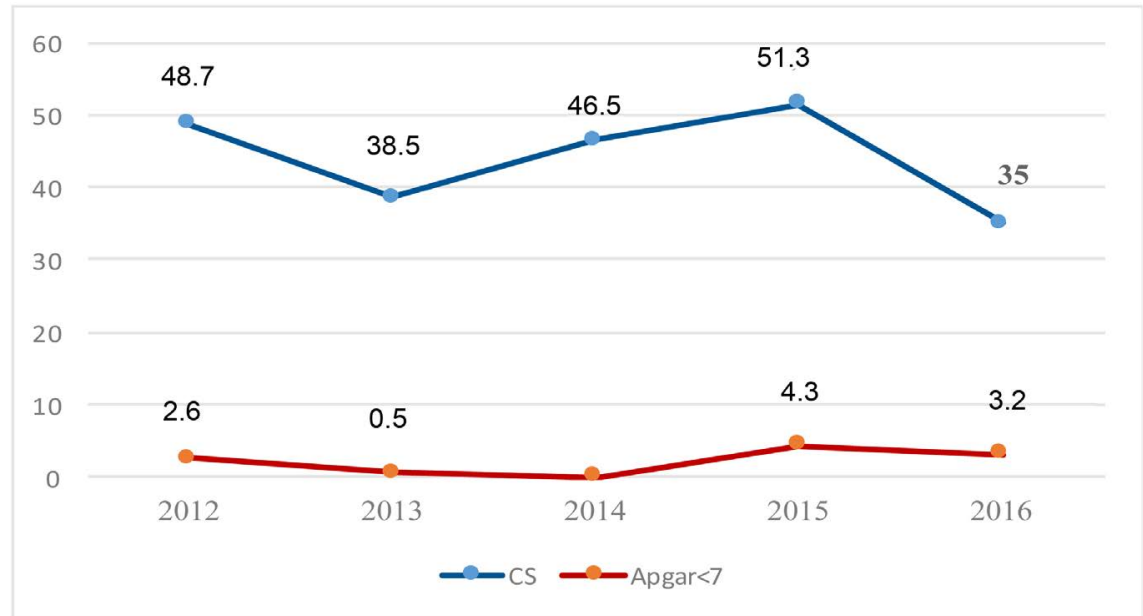

Figure 1. Distribution of patients according to Caesarean section and Apgar score rates for twin delivery.

Table 4. Distribution of patients according to the main indication of caesarean section.

\begin{tabular}{ccc}
\hline Indication & Number (n) & Percentage (\%) \\
\hline Fetal distress & 1396 & 29.2 \\
Obstructed or prolonged labour & 1040 & 21.7 \\
Breech presentation & 394 & 8.2 \\
Antepartum Haemorrhage & 267 & 5.6 \\
Twin delivery & 250 & 5.2 \\
Preeclampsia & 247 & 5.1 \\
Others indications & 1201 & 25 \\
Total & 4795 & 100 \\
\hline
\end{tabular}

Others indications included preterm delivery, umbilical cord dystocia, malpresentation of fetus, foetal abnormalities, elective CS, triple gestation, mother abnormalities. 
In breech presentation, the lowest rate of Apgar score below 7 (1.2\% - 1.6\%) was achieved when CS rate ranged between 52.4\% and 53.8\% (Figure 2).

Induction of labour was performed in $3.7 \%$ of patients in 2016 and $0.9 \%$ in 2012. It was associated with a highest rate of vaginal delivery: $81.4 \%$ versus $75.2 \%(\mathrm{p}=0.005 \mathrm{OR}=0.9[0.87-0.97])$.

\section{Discussion}

\subsection{Patient's Profile}

In our study, primary CS represented more than half of overall CS (72.5\%). To reduce CS rate, we need to focus on the primary indications for two main reasons: the important part of primary CS and the limited possibilities in scared uterus. Obviously, a scared uterus is immediately an obstetrical pathology that highly exposes to CS.

A proportion of $35.9 \%$ of patients who underwent CS was primiparous with vertex presentation.

\subsection{Analysis of Main Indications}

Caesarean section for suspected acute fetal distress was the largest group we had to deal with. Intrapartum asphyxia is defined as metabolic acidosis at birth with a $\mathrm{pH}$ less than 7.00 and base deficit greater or equal to $12 \mathrm{mmol} / \mathrm{l}$ [12]. In our center, diagnosis of fetal asphyxia was based on abnormal fetal heart rate at intermittent auscultation (less than 110 or more than 160 pulses per minute) associated to meconium in amniotic fluid. According to Bouiller et al., amniotic fluid aspects do not interfere with the occurring of a metabolic acidosis. Furthermore they concluded that Apgar score at $5^{\text {th }}$ minute seems predictive for a neonatal encephalopathy with $100 \%$ when Apgar score is less than 4 and $11 \%$ when it's greater than 6 [13]. In our study only $6.6 \%$ of newborns in whom fetal

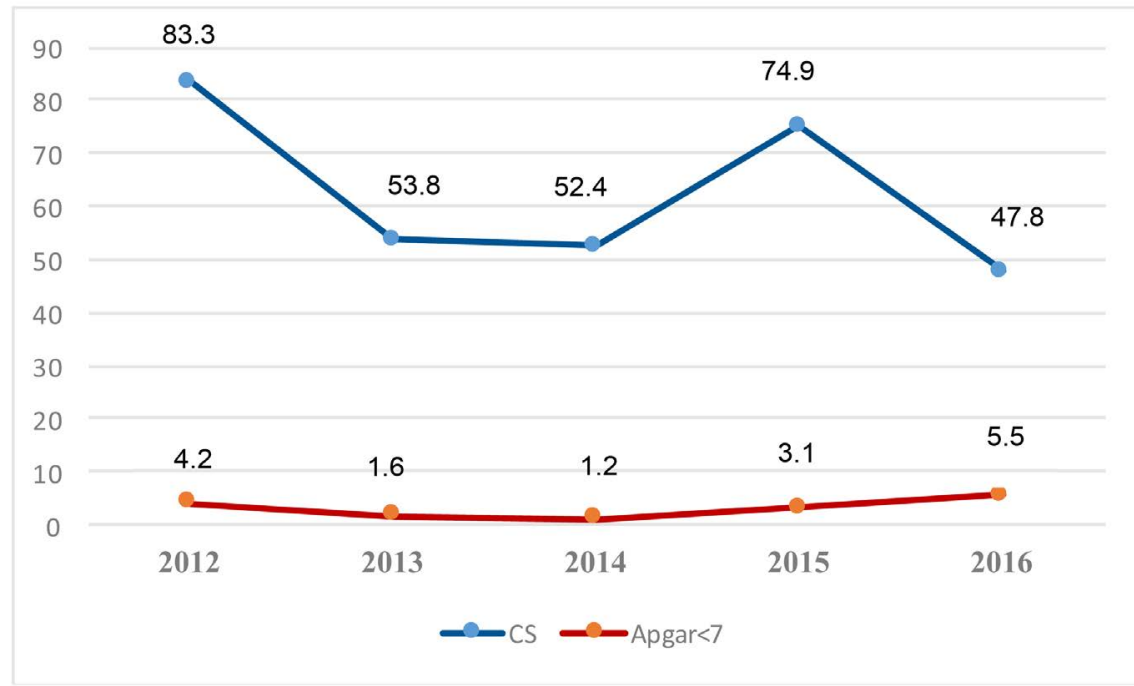

Figure 2. Distribution of patients according to Caesarean section and Apgar score rates for breech presentation. 
distress was suspected had an Agpar score less than 7 at the $5^{\text {th }}$ minutes. This raises the debate of criterion of diagnosis and predictive patterns of intrapartum asphyxia. Intermittent auscultation and amniotic fluid aspect are insufficient. According to certain publications, recurrent late or variable or prolonged decelerations, bradycardia with absent fetal heart rate (FHR) variability and sudden severe bradycardia are the FHR patterns that are predictive of severe fetal acidosis [13] [14]. Given that situation, our policies must emphasize on ways and means of proper diagnoses of foetal asphyxia risk. Cardiotocography availability will be a good help to succeed in reducing CS rate for foetal asphyxia risk. In addition, it's necessary to diagnose hidden foetal distress. This strategy is cost-effective for it could lessen the cost of deliveries as well as neonatal morbidity.

Hannah's term breech trial advocated a planned caesarean section for the singleton fetus in breech presentation at term [15]. This point of view impacted on twin delivery particularly when the first or the second twin is in non-vertex presentation [16] [17]. Thus, recent publications emphasize on the high CS rate in twin delivery [16] [17] [18]. In our facility, vaginal delivery was performed regardless of the second twin's presentation. We identified several trends: one obstetrical team who performed caesarean delivery when first twin was in breech presentation in 2012 and 2015, another obstetrical team (in 2013 and 2016) that attempted vaginal delivery in these cases.

In both cases (twin delivery and breech presentation), CS rate was lower in 2016. For twin delivery, the highest CS rate was occurred during the year 2015 while the highest rate of Apgar score less than 7. The situation was similar for breech presentation. These evidences do not argue for systematic CS for breech presentation in both single and twin pregnancies. It is necessary for this indication to find the best compromise between low CS rate and low neonatal morbidity. In our study, CS rates that provide the lowest neonatal morbidity ranged between $38.5 \%$ and $46.5 \%$ for twin delivery and between $52.4 \%$ and $53.8 \%$ for singleton breech presenting. That's the reason why we are encouraging vaginal delivery in breech-presenting first in twin and singleton with reasonable rate that allow a good neonatal outcome.

\subsection{An Obstetrical Audit to Reduce CS rate?}

According to Robson, it is necessary to up-date information collected on databases in order to be able to confirm whether there is an increase in maternal morbidity or mortality that justify a rising rate of CS [9]. During these five years, our database does not show such an increase that can justify an increasing rate of CS. Senior residents are performing a daily audit on a regular basis since 2016. The CS rates as well as CS for obstructed or prolonged labour were lower in 2016 than what was registered in previous years. This is the result of a better management of labour during that year 2016. So, we need some adjustment of obstetrical management to achieve the right rate of CS with the lowest maternal and neonatal morbidities. 


\subsection{Others Interventions}

Induction of labour can be an efficient alternative in some indications. This strategy was most often used in 2016. A Prostaglandin E2 analogue was almost exclusively used because of its availability. A dose of $25 \mu \mathrm{g}$ per 6 hours was administered by vaginal or oral route. The main indications were post-term pregnancy, preeclampsia after 37 weeks of gestation, pre-labour rupture of membranes and diabetes mellitus. The outcome of our study, namely the effectiveness of misoprostol, has already been demonstrated by several previous publications [11]. In low resource settings, the use of misoprostol is a safe method and can help reducing CS occurrence.

\section{Conclusions}

Even though there are sharp variations in CS rate between rural and urban areas, we can notice a steady maternal morbidity. Because, many CS were performed on the ground of suspected foetal distress without an accurate diagnosis. Moreover, further prospective studies are required to shed a light on predictive factors of intrapartum asphyxia. In addition, an availability of cardiotocography and $\mathrm{pH}$ of scalp can reduce unnecessary CS.

CS for breech presentation in singleton or twin delivery should not be systematic. A staff of obstetricians and neonatologists must discuss indications. Above a certain rate, caesarean section does not improve the Apgar score in twin and breech delivery.

An obstetrical audit provides information for the adjustment of management of delivery.

Safety and effectiveness of labour induction is demonstrated. It must take more and more place in obstetrical management.

\section{References}

[1] Souza, J., Guilmezoglu, A. and Lumbiganon, P. (2010) Caesarean Section without Medical Indications Is Associated with an Increased Risk of Adverse Short-Term Maternal Outcomes. The 2004-2008 WHO Global Survey on Maternal and Perinatal Health BMC Med, 8, 71 .

[2] WHO. (1985) Appropriate Technology for Birth. The Lancet, 2, 436-437.

[3] Hamilton, B.E., Martin, J.A. and Ventura, S.J. (2007) Births: Preliminary Data for 2006. National Vital Statistics Reports, 56, 1-18.

[4] Chong, C., Su, L.L. and Biswas, A. (2012) Changing Trends of Cesarean Section Births by the Robson Ten Group Classification in a Tertiary Teaching Hospital. Acta Obstetricia et Gynecologica Scandinavica, 91, 1422-1427. https://doi.org/10.1111/j.1600-0412.2012.01529.x

[5] National Agency of Statistics and Demography of Dakar. (2015) Investigation Demographic and Continuous Health (EDS-Continuous) 2014. Final Report, Calverton.

[6] Robson, M., Hartigan, L. and Murphy, M. (2013) Methods of Achieving and Maintaining an Appropriate Caesarean Section rate. Best Practice \& Research 
Clinical Obstetrics \& Gynaecology, 27, 297-308.

https://doi.org/10.1016/j.bpobgyn.2012.09.004

[7] Betran, A.P., Gulmezoglu, A.M., Robson, M., Merialdi, M., Souza, J.P., Wojdyla, D., et al. (2009) WHO Global Survey on Maternal and Perinatal Health in Latin America: Classifying Caesarean Sections. Reproductive Health, 6, 18.

https://doi.org/10.1186/1742-4755-6-18

[8] Vogel, J.P., Betran, A.P., Vindevoghel, N., Souza, J.P., Torloni, M.R., Zhang, J., et al. (2015) Use of the Robson Classification to Assess Caesarean Section Trends in 21 Countries: A Secondary Analysis of Two WHO Multicountry Surveys. The Lancet Global Health, 3, e260-e270. https://doi.org/10.1016/S2214-109X(15)70094-X

[9] Robson, M.S. (2001) Can We Reduce the Caesarean Section Rate? Best Practice \& Research Clinical Obstetrics \& Gynaecology, 15, 179-194.

https://doi.org/10.1053/beog.2000.0156

[10] Taylor, L. and Lon, A. (2016) Abnormal Labour. Obstetrics, Gynaecology \& Reproductive Medicine, 26, 85-88. https://doi.org/10.1016/j.ogrm.2015.12.002

[11] Roisin, R. and Fergus, M. (2016) Induction of Labour. Obstetrics, Gynaecology \& Reproductive Medicine, 26, 304-310. https://doi.org/10.1016/j.ogrm.2016.07.005

[12] Zupan Simunek, V. (2008) Définition de l'asphyxie intrapartum et conséquences sur le devenir. [Definition of Intrapartum Asphyxia and Effects on Outcome.] La Revue Sage-Femme, 7, 79-86. https://doi.org/10.1016/j.sagf.2008.04.008

[13] Bouiller, J.P., Dreyfus, M., Mortamet, G., Guillois, B. and Benoist, G. (2016) Asphyxie perpartum à terme: Facteurs de risque de survenue et conséquences à court terme. À propos de 82 cas. Journal de Gynécologie Obstétrique et Biologie de la Reproduction, 45, 626-632. https://doi.org/10.1016/j.jgyn.2015.06.022

[14] Martin, A. (2008) Rythme Cardiaque fotal pendant le travail: Définitions et interprétation. [Fetal Heart Rate during Labour.] Journal de Gynécologie Obstétrique et Biologie de la Reproduction, 37, S34-S45. https://doi.org/10.1016/j.jgyn.2007.11.009

[15] Hannah, M.E., Hannah, W.J., Hewson, S.A., Hodnett, E.D., Saigal, S. and Willan, A.R. (2000) Planned Caesarean Section vs. Planned Vaginal Birth for Breech Presentation at Term: A Randomised Multicentre Trial. Term Breech Trial Collaborative Group. The Lancet, 356, 1375-1383. https://doi.org/10.1016/S0140-6736(00)02840-3

[16] Easter, S.R., Lieberman, E. and Carusi, D. (2016) Fetal Presentation and Successful Twin Vaginal Delivery. American Journal of Obstetrics and Gynecology, 214, 116.e1-e10. https://doi.org/10.1016/j.ajog.2015.08.017

[17] Easter, S.R., Taouk, L., Schulkin, J. and Robinson, J.N. (2017) Twin Vaginal Delivery: Innovate or Abdicate. American Journal of Obstetrics and Gynecology, 216, 484-8.e4. https://doi.org/10.1016/j.ajog.2017.01.041

[18] Bateni, Z.H., Clark, S.L., Sangi-Haghpeykar, H., Aagaard, K.M., Blumenfeld, Y.J., Ramin, S.M., et al. (2016) Trends in the Delivery Route of Twin Pregnancies in the United States, 2006-2013. European Journal of Obstetrics \& Gynecology and Reproductive Biology, 205, 120-126. https://doi.org/10.1016/j.ejogrb.2016.08.031 